\title{
Research on Team Management Under the Blurred Organizational Boundary-Based on the perspective of Dynamic Capabilities
}

\author{
Hui $\mathrm{Li}^{1 *}$ \\ ${ }^{1}$ School of Economics and Management, Nanjing University of Aeronautics and Astronautics, Nanjing, Jiangsu, China \\ *Corresponding author.lihuihit666@163.com
}

\begin{abstract}
Boundary management under the fuzzy trend of organizational boundaries has become a research hotspot. The team has become an important focus of the dynamic management of organizational boundaries. On the basis of reviewing the perspective of defining organizational boundaries, this research clarifies the characteristics of fuzzy boundaries, and analyzes the necessity of dynamic management of leadership, R\&D, production, and marketing under the fuzzy characteristics of organizational boundaries from the perspective of dynamic capabilities and specific countermeasures. Finally, the team's co-construction mechanism was discussed.
\end{abstract}

Keywords: Blurred organizational boundaries, team management, dynamic capabilities

\section{INTRODUCTION}

The problem of organizational boundary is an important content of organizational theory research. As an organism, an organization needs to use rational concepts to implement strategies, produce operations, and create value on the premise of defining internal and external boundaries. Organizational boundaries are becoming blurred in a rapidly changing market environment. The blurred boundaries have impacted the original stylized management system of the enterprise and brought challenges to the organization managers. What kind of response system should the organization adopt to perceive the fuzzy organizational boundaries? How to reconstruct the boundaries of influence? How to do a good job in frontier management? As the most flexible and perceptual unit level, the team should have more operating space from the perspective of dynamic capabilities. This article will summarize the characteristics of fuzzy organizational boundaries on the basis of combing the relevant literature, and then try to use the perspective of dynamic capabilities to clarify the necessity of team management at different unit levels in the organization and specific countermeasures, and discuss the team building mechanism. In order to explore the team management method under the blurred organizational boundary from a new perspective.

\section{ORGANIZATIONAL BOUNDARY DEFINITION AND BOUNDARY BLUR}

\subsection{Defining Organizational Boundaries}

The definition of organizational boundaries stems from the cognition of the organization. The boundary of the organization externally interprets the boundaries of the organizational mission in the scope of the implementation of business activities, and internally forms the internal structure and management environment. Organizational boundaries can help companies find their own position in the social division of labor, and at the same time construct their internal value creation methods. Tu [1] combed the definition of organizational boundaries from the perspectives of economics and management, and concluded based on the commonalities of different research perspectives. He believed that whether the organization is regarded as a combination of a series of similar market enterprises, or the organization is regarded as a collection of unique resources and abilities, or thinking that an organization is the accumulation and creation of knowledge, etc., organizational boundaries are set and defined in accordance with the effective realization of the organization's goals. In the theory of enterprise dynamic capabilities, the boundary of an enterprise is determined by the uniqueness and difficulty of imitation of its 
dynamic core capabilities. Dynamic capabilities are derived from long-term organizational learning and knowledge accumulation. They are the ability to quickly establish, integrate, and reconfigure internal and external resources in an organization to quickly adapt to rapid changes in the environment.

The environment faced by the organization is dynamic, complex and asymmetrical in information. Many scholars regard the organization as a cognitive organism or a dynamically evolving body of knowledge that can have perception. In the era of knowledge economy, the boundaries of organizations will be redefined, and flexibility, absorptive capacity, integration and innovation have become key factors for corporate organizations to establish competitive advantages.

\subsection{Fuzzy Characteristics Of Organizational Boundaries}

Organization is a group composed of different individuals with a common goal as the direction of struggle. In the process of organization, a multi-level and multi-form boundary has been formed. There are internal boundaries between units within an organization, and various external boundaries are also formed between different organizations. These boundaries may exist as physical boundaries, social boundaries, and psychological boundaries. The various boundaries of the organization may be solidified into rules and regulations or internalized in the cognition and behavior of the members of the organization.

With the development of the times, technological progress and changes in consumption concepts have greatly increased the complexity of the environment, and competition among enterprises has become more intense, making it increasingly difficult for enterprises to obtain a relatively stable environment. The original system that brings competitive advantage may be quickly replaced or subverted, and it is difficult for companies to win the initiative in the fierce competition. The blurring of organizational boundaries has shaken the original boundaries of the organization to varying degrees, showing the characteristics of moving from the organizational level to the work unit level, from focusing on physical boundaries to social and psychological boundaries, and from marginalization to centralization in the understanding of organizational boundaries.

\subsubsection{The Organizational Level Is Moved To The Unit Level}

The blurring trend of boundaries means that the original internal and external boundaries are shaken or even broken. Through flattening, reducing the level of communication, and granting greater autonomy to lowerlevel units can they enhance their ability to cope with rapidly changing environments. The structure at the unit level, like a cell, can quickly perceive changes, absorb information, adjust strategies and respond to challenges. The dynamics and permeability of its boundaries play a vital role in the identification, filtering, and transformation of information and resources.

\subsubsection{From Focusing On Physical Boundaries To Social And Psychological Boundaries}

The research focus on organizational boundaries has gradually transcended physical boundaries, and tends to be the identification boundaries of social and psychological boundaries [2]. In the continuous interaction process of the members of the organization, a consistent identity in the three dimensions of cognition, emotion and action has been formed. The shared mental model [3] and the sense of organizational identity have received more attention in the identity boundary. The psychological tacit understanding formed by interaction between members is easy to cooperate, and this boundary is more flexible and cohesive. The change of organizational boundaries is two-way. Inwardly, it shows that the inherent systems and psychological barriers between members of different departments and different levels are diluted or eliminated. Organizational members hope that the internal atmosphere is harmonious and advocate innovation; outwardly, it shows that they care about consumers' needs, the construction of organizational image, and social embedding [4], promote the recognition of external stakeholders and the cocreation of value.

\subsubsection{The Perception Of Organizational Boundaries Shifts From Marginalization To Centralization Of Capabilities}

The dissolution of the inherent external boundary strengthens the demand for the capability boundary generated by dynamic capabilities. The more the external environment changes, the concentration of internal core capabilities is required, that is, the "unchanged" should respond to all changes. The "unchanged" here is Refers to the shaping and persistence of dynamic core capabilities, which emphasize innovation, adaptability and cohesion. The physical boundary is fading, while the social and psychological boundary is strengthening, which means that the members of the organization seek to identify and produce the constructive behavior of the identity center. 


\section{TEAM MANAGEMENT UNDER DYNAMIC CAPABILITIES}

\subsection{Dynamic Capabilities And Team Decision- Making Advantages}

\subsubsection{Dynamic Capabilities}

Dynamic capability is the ability of an enterprise to integrate, establish and re-allocate internal and external resources to adapt to rapid changes in the environment, and it is the ability to update the enterprise [5]. Jian and Liu [6] combined the cognitive perspective to construct a relatively complete dynamic capability model, including organizational cognitive renewal, network boundary expansion, relationship integration, resource integration, and big data capabilities. Dynamic capabilities enable companies to absorb and transform valuable external information, identify and use market opportunities and reallocate resources, develop new products and expand new markets, and maintain competitive advantages.

\subsubsection{Team Decision-Making Advantage}

Relying solely on the unique knowledge of individual members can no longer meet the needs of development in the fierce market competition. The team enables the organization to respond more quickly, flexibly and appropriately to the market. The communication and sharing of knowledge by building a team has become a necessary way for an enterprise to survive and develop. Use the heterogeneity of knowledge among team members to discover innovative ideas, and work together to realize new product or service innovation [7].

\subsection{Team Management Under Dynamic Capabilities}

Most of the tasks faced by enterprises require a variety of complex skills and experience to complete. In a complex and changeable environment, the team is more flexible in adapting to the market environment and responds more quickly. The fuzzy characteristics of the organizational boundary enable the team to gain a greater voice and space for operation, and it also puts forward new requirements for its management concepts and practices in various aspects such as leadership, $R \& D$, production, and sales. From the perspective of dynamic capabilities, the dynamic perception, absorption, integration, and response capabilities of each unit level need to be cultivated more seriously, and the necessity of dynamic management is self-evident.

\subsubsection{Leadership Team}

In order to cope with fierce competition, companies need to introduce a large number of new employees with adventurous and innovative spirit. The addition of fresh blood will change the management style of the team. New employees need more space to display their talents and abilities, and they need a relaxed and good atmosphere of innovation. If the leader cannot fully pay attention to the inner level of the employees, then the corresponding creative potential of the employees may be difficult to fully explore, which is not conducive to the realization of the value of the employees and the achievement of the team performance. Employees who receive attention can actively try different innovation paths, which will stimulate their inherent sense of mission and belonging, and increase their enthusiasm for work. Leaders in complex situations need to have multiple leadership abilities such as change, tolerance, empowerment and authoritarianism, and frequent interactions with organization members, sensitively capture environmental changes and respond quickly, and promote new thinking, new methods, new products, etc. A large number of adaptive behaviors have emerged [8].

\subsection{2. $R \& D$ Team}

Product R\&D is a complex organizational activity that covers multi-disciplinary and multi-domain knowledge. It faces a variety of cross-border integration problems and uncertainties, and requires close cooperation and effective communication among team members. The innovation activities of an enterprise mainly come from the R\&D team. How to organize and operate the $R \& D$ team scientifically is a problem that the enterprise must solve. The R\&D team is composed of people who are quite different in many aspects, and different knowledge, experience, thinking styles, etc. make the knowledge exchange between $R \& D$ team members certain obstacles [9]. R\&D teams often search for resources, information and knowledge related to innovation by crossing their own boundaries. Heterogeneous knowledge is the source of creativity [7]. Communication and exchanges between $R \& D$ team members can reduce the barriers to information sharing and can form A good interactive relationship can quickly collaborate and overcome difficulties when facing key challenges. The $R \& D$ process is extremely risky, and it is necessary to tolerate the atmosphere of failure and learn from failure [10].

\subsubsection{Production Team}

With the development of the times, consumers have mostly shifted from convergent consumption to personalized consumption; from price-oriented to valueoriented. Consumers' demands for experience, emotion, and culture have gradually become stronger. For enterprises, it is necessary to establish an experiential way of thinking [11], to reset the design and production methods of products, and to adopt customized production methods based on the individual needs of customers to enhance the flexibility of production. Customized 
strategies can promote customer participation, stimulate innovative new ideas, and establish good customer trust [12].

\subsubsection{Marketing Team}

Marketers need to have keen market judgment ability, strong learning ability and good service attitude and communication skills. Establish a customer-centric service concept and service system, clarify the individual needs of customers, formulate research marketing plans, establish customer files in the consensus with customers, and continue to provide high-quality after-sales services to enhance customers in the entire marketing process Satisfaction. With the diversification of production and individual differences in consumer demand, customers not only pursue the use value of goods or services, but also pay more attention to experience value and cultural value. The experience value and self-identification value of the product are created in the process of customer's personalized experience of the product [13]. The customer's individualized experience is highly dependent on the individual's perception. The marketing team should provide open marketing scenarios or interestbased communities, and continue to interact with customers in a heterogeneous manner. While satisfying customers' sense of self-efficacy, customers can deepen the cognition of products or services, which can enhance the trust and loyalty of customers, while also exploring and constructing new value co-creation models [14].

\subsection{Team Building Mechanism}

Team management is a design problem about incentive mechanism and identification mechanism. There are indispensable conflicts and contradictions among team members. Team members need to communicate and run-in continuously to build a higher degree of trust and strengthen their mutual Understanding and willingness to collaborate, so as to promote the achievement of team goals.

\subsubsection{Trust Mechanism}

Contradictions and conflicts among team members may cause invisible psychological effects on employees, reduce mutual trust and willingness to collaborate among members, team leaders should do a good job in conflict management, that is, through conflicts to retain heterogeneous views, but also Make conflict a good opportunity to promote mutual understanding between members and maintain the vitality and consistency of the team. Members trust each other, maintain an open attitude to each other, learn from each other, learn from each other's strengths, and communicate sincerely to enhance the cohesion and creativity of the team.

\subsubsection{Incentive Mechanism}

A good team incentive mechanism can fully mobilize the enthusiasm of team members, so that individuals and teams can focus on their efforts in a clear direction. The team incentive mechanism can be divided into positive reinforcement mechanism and negative reinforcement mechanism. The positive strengthening mechanism is mainly to establish an effective remuneration system, an appropriate target system, etc., to mobilize the enthusiasm of team members, increase team output, and achieve good performance. The negative reinforcement mechanism is to reduce or eliminate inappropriate and lossy situations through certain measures, which can avoid internal friction points in the team's operation and enable the team to concentrate on achieving the goal.

\section{CONCLUSION}

This article cuts into research from the perspective of dynamic capabilities, reviews the perspective of defining organizational boundaries, analyzes the characteristics of fuzzy boundaries, combines research frontiers in multiple fields, clarifies the necessity of team dynamic management, and then explores the team's coconstruction mechanism. The newly constructed team management unit (leadership, $R \& D$, production, sales) has dynamic capabilities of high perception, absorption, adjustment, and response, enabling organizations to establish competence boundaries based on their own dynamic capabilities under the condition of blurred boundaries, and make quick and Appropriate decisionmaking, innovative products or services, resolve crises, and win space for survival and development.

\section{AUTHORS' CONTRIBUTIONS}

This research clarifies the characteristics of fuzzy boundaries, and analyzes the necessity of dynamic management of leadership, $\mathrm{R} \& \mathrm{D}$, production, and marketing under the fuzzy characteristics of organizational boundaries from the perspective of dynamic capabilities and specific countermeasures. Finally, the team's co-construction mechanism was discussed.

\section{ACKNOWLEDGMENTS}

I would like to thank the following persons for their help and support during my research and writing for this thesis.

First of all, I want to thank Professor Peng Can, my thesis advisor. He has talked with me several times during the whole thesis-writing process, discussing my research ideas and approaches and giving me advice on how to conduct the research and present it on paper. 
Secondly, I want to thank my classmates and friends who have given me much help and comfort.

\section{REFERENCES}

[1] X.Y. Tu, Organization of knowledge perspective: concepts, boundaries and research topics, in: $\mathrm{X}$. Fang (Eds.), Studies in Science of Science, vol. 30, Peking, 2012, pp. 145-147. DOI: https://doi.org/10.3969/j.issn.1002736X.2009.09.036

[2] X.Q. Li, Organizational Boundaries of Enterprises: A Re-examination Based on Different Theoretical Perspectives, in: Reformation and Strategy, vol. 25, Guangxi, 2009, pp. 1378-1387. DOI: https://doi.org/10.16192/j.cnki.10032053.2012.09.0 $\underline{13}$

[3] Y. Shi, N. Li, Team effective communication and the construction of a shared mental model, in: Scientific Management Research, vol. 25, Peking, 2007, pp. 102-105 DOI: https://doi.org/10.19445/j.cnki.15$1103 / \mathrm{g} 3.2007 .01 .026$

[4] H. Yang, L.P. Chen, Knowledge learning between enterprises from the perspective of social network embeddedness, in: Southeast Academic Research, Fujian, 2008, pp. 42-47. DOI: https://doi.org/10.3969/j.issn.10081569.2008 .04 .006

[5] D.J. Teece, G. Pisano, A. Shuen, Dynamic capabilities and strategic management, in: Strategic management journal, vol. 18, John Wiley \& Sons, Ltd, New Jersey, 1997, pp. 509-533. DOI: https://doi.org/10.1142/9789812796929 0004

[6] Z.Q. Jian, N. Liu, Dynamic capability construction mechanism and service innovation performance: Research on service platform transformation based on France, in: Science of Science and Management of S.\& T, vol. 40, 2019, pp. 84-101. DOI: https://doi.org/CNKI:SUN:GJJR.0.2019-10-084

[7] K. Sun, Y.T. Liu, X.T. Liu, Research on the Influence of Knowledge Heterogeneity of R\&D Team on Knowledge Sharing, in: Information Science, vol. 34, Shaanxi, 2016, pp. 59-64. DOI:

https://doi.org/10.13833/j.cnki.is.2016.02.013

[8] X.M. Zhu, J.R. Chen, H.Q. Zhou, Will complex adaptive leadership stimulate employees' innovative behavior?_-Based on the perspective of selfdetermination theory, in: Lanzhou Academic Journal, vol. 11, Lanzhou, 2020, pp. 128-138. DOI: https://doi.org/10.3969/j.issn.1005$\underline{3492.2020 .11 .011}$
[9] N. Liu, J.S. Jia, An empirical study on the relationship between R\&D team diversity, knowledge sharing and innovation performance, in: Nankai Business Review, Tianjin, 2012, pp. 87-94+105. DOI: https://doi.org/10.3969/j.issn.10083448.2012.06.010

[10] J.S. Li, Y. Yu, Research on the flexible organization model of innovative enterprises based on R\&D risk, in: R.P. Mu (Eds.), Science \& Technology Progress and Policy, vol. 31, Science Press, Peking, 2014, pp. 97-102. DOI: https://doi.org/10.6049/kjjbydc.2013020410

[11] H.L. Sang, G.S. Tian, Experience the customization of manufacturing in the era of economy, in: Academic Exchanges, Harbin ,2016, pp. 152-156. DOI: $\quad$ https://doi.org/10.3969/j.issn.1000$\underline{8284.2016 .08 .027}$

[12] J. Wang, L.J. Cheng, Q.M. Song, Research on Custom Satisfaction Based on Customer Participation, in: Chinese Journal of Management., vol. 5, 2008, pp. 391. DOI: https://doi.org/10.3969/j.issn.1672884X.2008.03.015

[13] X.C. Yang, X.X. Xu, X.B. Tao, Research on the Mechanism of Value Co-creation Based on Experiential Marketing_-Taking the Automobile Industry as an Example, in: Management Review, vol. 28, Peking, 2016, pp. 232-240. DOI: https://doi.org/10.14120/j.cnki.cn115057/f.2016.05.020

[14] S.R. Jiang, H. Qiao, S. Zhang, Research Frontiers of Value Co-creation: Ecosystem and Business Model Innovation, in: Management Review, vol. 32, Peking, 2020, pp. 3-17. DOI: https://doi.org/10.14120/j.cnki.cn115057/f.2020.02.001 